Cumhuriyet International Journal of Education-CIJE

e-ISSN: 2147-1606

Vol 4 (1), 2015, 1 - 20

\title{
Content Development Process in Distance Education: Example of Gazi University Institute of Information
}

\author{
Öznur ÇAKIR ${ }^{1}$, M. Hanefi CALP ${ }^{2}$, Ahmet DOĞAN ${ }^{3}$
}

\begin{abstract}
Summary
\section{INTRODUCTION}

In our days, use of information and communication technology in education process has caused to develop many new concepts. One of these concepts is distance education. In recent times we have experienced information age, distance education has developed as well as advanced internet technology, and with the help of this technology, opportunity of providing education free from time and place has been reached. This change supplied to form sub-concepts under the concept of distance education. Computer-assisted instruction for education through computer, web-based education, online education or e-learning concepts for education through Internet were started to be preferred. In the first part of the work, concept of distance education and transition period to distance education were evaluated briefly, and importance of content development in distance education to increase quality of education was emphasized. In the second part of the work, content development process in distance education was thoroughly mentioned. In the third part, Gazi University Institute of Information Content Development Process in Distance Education was represented in details. In the fourth part, there are results and suggestions of the work.
\end{abstract}

\section{METHOD}

In this study, the process between the preparation of course content by the instructors and the implementation of these content in to education management system is explained thoroughly and indicated by diagrams in the scope of Gazi University, Informatics Institute Distance Education Program. Also, previously developed models for this process are studied and their differences are reveald. Thus, it is aimed to provide a standard for supporting electronic course contents with appropriate audio-visual materials and presenting them clearly. It is thought that this study will play an important role at improving visual and educational quality of course contents in distance education program and organizing this process.

\section{FINDINGS}

It is thought that the work will increase visual and educational quality of course contents in distance education program, and have an important place to organize this process.

\footnotetext{
${ }^{1}$ Expert, Gazi University, Turkey, ocakir@gazi.edu.tr

2 Res. Assist., Gazi University, Turkey, mhcalp@gazi.edu.tr

${ }^{3}$ Res. Assist., Gazi University, Turkey, doganahmet@gazi.edu.tr
} 


\section{DISCUSSION}

Distance education as a heavily demanded education system day by day in parallel with use and growth of internet has been changing education practice. Success of distance education is in direct proportion to quality of supplied contents. It is important to present these contents in appropriate visual representation with expectation of today's Internet users as well as being content-rich and qualified. In this manner, preparing course contents in ecourse, e-exam format is always expensive process, and requires demanding working. However, this process can be diminished, and easier notably with the help of use of practical content development technologies. Accordingly, contents can be prepared practically, and rapidly. At that point, importance of the work can be understood. Being quality of developed contents for distance education is related with not only the number or varies of used tools, but also use of content development process model.

\section{RECOMMENDATIONS}

As a result of the work, some mistakes related with content development process in distance education were found out. Some suggestions were offered to correct these mistakes. First of all, student requirements should be taken into consideration in analyze step by designing Internet Technologies Aided Distance Education processes. Other design steps should start after determining characteristic features of students. Application which will improve communication in Internet Technologies Aided Distance Education coursed should be given importance, because communication infrastructure increases motivation and success in learning. Internet Technologies Aided Distance Education should be supplied by giving internet applications in the right place at the right time to increase students' learning motivation and attract their interest to the course. Necessary internet applications and time, labor, and cost should be determined by analyzing content structure of Internet Technologies Aided Distance Education courses. 